\title{
Rye grains and the soil derived from under the organic and conventional rye crops as a potential source of biological agents causing respiratory diseases in farmers
}

\author{
Wioletta A. Żukiewicz-Sobczak ${ }^{1}$, Grażyna Cholewa ${ }^{1}$, Ewelina Krasowska ${ }^{1}$, Jolanta Chmielewska-Badora ${ }^{1}$, \\ Jacek Zwoliński², Paweł Sobczak ${ }^{2}$
}

\author{
'Department of Allergology and Environmental Hazards, Institute of Rural Health, Lublin, Poland \\ Head of Department: Wioletta A. Żukiewicz-Sobczak PhD \\ 2Department of Food Engineering and Machines, University of Life Sciences, Lublin, Poland \\ Head of Department: Prof. Kazimierz Zawiślak
}

\begin{abstract}
Introduction: Due to the specific work environment, farmers are exposed to various biological occupational hazard. Among these factors significant are fungi present in the grain and also in the soil. The fungi may be the cause of human diseases including skin infections, asthma, allergic rhinitis and many others.

Aim: The aim of this study was to quantify and identify species of fungi colonizing rye grain samples and the soil under cultivation.

Material and methods: The material consisted of grain and soil samples from two agricultural systems: organic and conventional.To determine the concentration and composition of fungi in collected samples, two media: Malt Agar (MA, Becton, Dickinson and Company) and Potato Dextrose Agar (PDA, Becton, Dickinson and Company) were used.The composition of species in fungal flora was determined using macroscopic and microscopic methods. The isolates of fungi were ranked in the appropriate classes of biosafety BSL.

Results: The most frequently isolated fungi from organic rye grain, regardless of the media used, were species: Aureobasidium pullulans and Alternaria alternata. In conventional farms, most species isolated from rye grain were: Aureobasidium pullulans, Cladosporium oxysporum, Alternaria alternata and yeast-like fungi. Most often species isolated from the soil was Penicillium citreo-viride.

Conclusions: All the results of the research demonstrate the potential hazard to the health of people working in agriculture. Significant exposure of this professional group is associated with the presence of harmful biological agents present in the grain and soil from its cultivation.
\end{abstract}

Key words: organic agriculture, conventional crops, molds, alveolitis allergica.

\section{Introduction}

Conventional farming relies on the use of chemical fertilizers and pesticides, while organic farming rejects any chemical fertilizers. According to data provided by the Inspection of Agricultural and Food Quality in recent years, organic farming in Poland is growing rapidly. Continued support of the European Union in this area and the growing interest in organic products are the factors that determine the development. In the first half of 2012, the increase in the number of organic producers was reported in all 16 provinces. The vast majority of organic producers in Poland is organic agricultural producers. As at 30 June 2012, they accounted for approximately 98\% of all manufacturers [1].

Rye (Secale cereale) is called the "European grain" as more than $78.7 \%$ of its production is grown in Central, Eastern and Northern Europe. In Poland, it is second only to wheat (27.3\%), acreage (16.3\%) of all types and forms of cereals in total plantings. The world's leading producers of wheat are Russia, Germany, Poland, Belarus and Ukraine. The total production of these five countries is two thirds of world production of rye grain [2].

Address for correspondence: Wioletta A. Żukiewicz-Sobczak PhD, Department of Allergology and Environmental Hazards, Institute of Rural Health, 2 Jaczewskiego St, 20-090 Lublin, Poland, phone: +48 698143 743, e-mail: wiola.zukiewiczsobczak@gmail.com Received: 13.08.2013, accepted: 17.09.2013. 
Table 1. Fungi identified in samples of rye grain taken from organic and conventional crops isolated on Malt Agar (MA) and Potato Dextrose Agar (PDA)

\begin{tabular}{|c|c|c|c|c|}
\hline \multirow{2}{*}{ Isolated fungi } & \multicolumn{2}{|c|}{ Organic farming [\%] } & \multicolumn{2}{|c|}{ Conventional farming [\%] } \\
\hline & PDA & MA & PDA & MA \\
\hline Acremonium sp. & 0.5 & 0.0 & 0.0 & 2.6 \\
\hline Acremonium strictum & 0.0 & 0.0 & 0.8 & 1.7 \\
\hline Alternaria alternata & 12.2 & 32.2 & 5.8 & 10.3 \\
\hline Alternaria chlamydospora & 0.0 & 0.0 & 0.8 & 0.0 \\
\hline Alternaria sp. & 0.0 & 3.4 & 0.4 & 6.0 \\
\hline Aspergillus candidus & 0.0 & 0.0 & 0.4 & 5.1 \\
\hline Aspergillus versicolor & 0.0 & 0.0 & 1.2 & 0.0 \\
\hline Aureobasidium pullulans & 57.0 & 21.8 & 17.9 & 6.0 \\
\hline Basipetospora rubra & 0.0 & 0.0 & 0.0 & 2.6 \\
\hline Beauveria sp. & 0.0 & 0.0 & 0.0 & 0.9 \\
\hline Cladosporium cladosporioides & 0.0 & 0.0 & 0.0 & 0.9 \\
\hline Cladosporium herbarum & 1.8 & 0.0 & 10.9 & 0.9 \\
\hline Cladosporium macrocarpum & 5.4 & 4.6 & 3.9 & 4.3 \\
\hline Cladosporium oxysporum & 0.9 & 0.0 & 17.9 & 0.0 \\
\hline Cladosporium sphaerospermum & 1.4 & 3.4 & 1.9 & 1.7 \\
\hline Fusarium cerealis & 0.0 & 0.0 & 0.4 & 0.0 \\
\hline Fusarium equiseti & 0.0 & 0.0 & 0.4 & 0.0 \\
\hline Fusarium poae & 0.0 & 1.1 & 0.0 & 0.0 \\
\hline Fusarium sp. & 0.0 & 5.7 & 0.0 & 4.3 \\
\hline Fusarium tricinctum & 0.0 & 0.0 & 0.8 & 1.7 \\
\hline Gonatobotrys sp. & 2.3 & 1.1 & 3.1 & 6.8 \\
\hline Mucor hiemalis & 0.0 & 1.1 & 0.0 & 1.7 \\
\hline Mucor plumbeus & 0.0 & 2.3 & 0.0 & 0.0 \\
\hline Mycelia sterilia & 3.6 & 9.2 & 4.3 & 9.4 \\
\hline Nigrospora sp. & 0.0 & 0.0 & 0.0 & 0.9 \\
\hline Paecilomyces sp. & 0.0 & 0.0 & 0.8 & 0.0 \\
\hline Paecilomyces variotii & 0.0 & 0.0 & 0.0 & 3.4 \\
\hline Penicillium citreo-viride & 0.0 & 1.1 & 0.0 & 0.0 \\
\hline Penicillium crustosum & 0.0 & 1.1 & 0.0 & 0.0 \\
\hline Penicillium cyclopium & 0.0 & 0.0 & 0.0 & 0.9 \\
\hline Penicillium expansum & 0.0 & 2.3 & 3.5 & 2.6 \\
\hline Penicillium nalgiovense & 0.0 & 0.0 & 1.9 & 1.7 \\
\hline Penicillium rugulosum & 0.0 & 0.0 & 0.0 & 0.9 \\
\hline Penicillium sp. & 0.0 & 1.1 & 0.4 & 0.9 \\
\hline Penicillium tricolor & 0.0 & 2.3 & 0.0 & 3.4 \\
\hline Penicillium verrucosum & 1.8 & 0.0 & 0.0 & 0.0 \\
\hline Penicillium viridicatum & 0.0 & 0.0 & 1.9 & 2.6 \\
\hline Rhizopus oryzae & 0.5 & 1.1 & 0.0 & 0.0 \\
\hline Trichophyton sp. & 0.5 & 0.0 & 0.0 & 0.0 \\
\hline Ulocladium chartarum & 1.4 & 0.0 & 4.7 & 7.7 \\
\hline Yeast-like fungi & 10.9 & 3.4 & 16.0 & 8.5 \\
\hline Total & 100 & 100 & 100 & 100 \\
\hline
\end{tabular}


Table 2. Concentration of fungi in rye grain samples taken from organic and conventional crops

\begin{tabular}{ccccc}
\hline \multirow{2}{*}{ Sample no. } & \multicolumn{2}{c}{ Organic farming $\left[\times 10^{3}\right.$ CFU/g] } & \multicolumn{2}{c}{ Conventional farming $\left[\times 10^{3}\right.$ CFU/g] } \\
\cline { 2 - 5 } & PDA & MA & PDA & MA \\
\hline 1 & 26.5 & 20 & 54 & 9.5 \\
\hline 2 & 25 & 22 & 62 & 28.5 \\
\hline 3 & 45 & 11 & 7.5 & 22 \\
\hline 4 & 51 & 18.5 & 25 & 22 \\
\hline 5 & 74.5 & 0.5 & 36 & 17.5 \\
\hline 6 & 51.5 & 13 & 15 & 13 \\
\hline 7 & 27.5 & 5.5 & 51.5 & 14 \\
\hline 10 & 35 & 19 & 41.5 & 20 \\
\hline Mean & 24.5 & 11 & 29.5 & 20.7 \\
\hline
\end{tabular}

Agricultural producers are exposed to a number of different health risks associated with their work environment and the way it is carried out, and these among other things are: toxic agents, noise, vibration, adverse climate, the high cost of labor power, high static load associated with work in the forced position and harmful biological agents including organic dust $[3,4]$.

\section{Aim}

The ability of fungi and their metabolites inhaled with the dust by agricultural producers which often leads to the development of respiratory diseases and allergies prompted the authors to carry out research in this direction.

The aim of this study was to quantify and identify species of fungi colonizing rye grain samples and the soil under cultivation. The samples came from conventional and organic farms located in the Lublin province. In addition, identified fungi were classified into classes of Biosafety Levels (BSL).

\section{Material and methods}

The material consisted of grain and soil samples from two agricultural systems: organic and conventional in the Lublin province (10 samples of grain and soil from each system of cultivation - a total of 40 samples).

To determine the concentration and composition of fungi in collected samples, two media: Malt Agar (MA, Becton, Dickinson and Company) and Potato Dextrose Agar (PDA, Becton, Dickinson and Company) were used and the method of plate dilution with the addition of Tween 80 . The study was conducted in two parallel repetitions. The PDA isolates were incubated at $24^{\circ} \mathrm{C}$ for
$144 \mathrm{~h}$ and MA isolates were incubated at $30^{\circ} \mathrm{C}$ for $72 \mathrm{~h}$ and at room temperature for another $72 \mathrm{~h}$. The composition of species in fungal flora was determined using macroscopic and microscopic methods and taxonomic keys and atlases [5-10] and expressed in colony forming units per gram (CFU/g).

The $\mathrm{pH}$ of the soil samples was tested with waterproof pH meter (Elmetron, CP-411). Isolated species of fungi were ranked in the appropriate classes of biosafety BSL.

\section{Results}

\section{Identification of fungi}

In the samples of rye grain from organic farms, most frequently the following fungi were found: Aureobasidium pullulans (PDA - 57.0\%, MA - 21.8\%), Alternaria alternata (PDA - 12.2\%, MA - 32.2\%), yeast-like fungi (PDA - 10.9\%, 3.4\% - MA), mycelia sterilia (PDA - 3.6\%, MA - 9.2\%), Cladosporium macrocarpum (PDA - 5.4\%, MA $4.6 \%$ ). The samples of rye grain taken from conventional farms were dominated by: Aureobasidium pullulans (PDA - 17.9\%, MA - 6.0\%), Cladosporium oxysporum (PDA $17.9 \%$, MA - 0\%), yeast-like fungi (PDA - 16.0\%, MA $8.5 \%)$, Alternaria alternata (PDA - 5.8\%, MA - 10.3\%), Cladosporium herbarium (PDA - 10.9\%, MA - 0.9\%), Ulocladium chartarum (PDA - 4.7\%, MA - 7.7\%), Gonatobotrys sp. (PDA - 3.1\%, MA - 6.8\%). The most diverse in terms of diversity of isolates were samples from rye grain from conventional crops, isolated on MA, and the least diverse sample came from rye grain from organic farms isolated on PDA (Table 1).

The concentration of fungi in samples derived from rye grain from organic farms isolated on PDA was in the 
Table 3. Identified fungi in soil samples taken from the rye crops of organic and conventional farming isolated on Malt Agar (MA) and Potato Dextrose Agar (PDA)

\begin{tabular}{|c|c|c|c|c|}
\hline \multirow{2}{*}{ Isolated fungi } & \multicolumn{2}{|c|}{ Organic farming [\%] } & \multicolumn{2}{|c|}{ Conventional farming [\%] } \\
\hline & PDA & MA & PDA & MA \\
\hline Alternaria alternata & 0.7 & 3.8 & 2.9 & 3.1 \\
\hline Alternaria chlamydospora & 0.0 & 0.0 & 0.0 & 0.3 \\
\hline Aspergillus versicolor & 1.6 & 0.0 & 3.2 & 9.8 \\
\hline Beltrania rhombica & 0.0 & 0.0 & 0.0 & 1.0 \\
\hline Chaetomium atrobrunneum & 0.0 & 0.6 & 0.0 & 0.0 \\
\hline Chaetomium sp. & 0.0 & 0.0 & 0.8 & 0.0 \\
\hline Cladosporium herbarum & 1.6 & 0.0 & 1.4 & 0.0 \\
\hline Cladosporium macrocarpum & 0.0 & 0.0 & 1.0 & 0.0 \\
\hline Cladosporium oxysporum & 0.7 & 0.0 & 0.0 & 2.2 \\
\hline Fusarium cerealis & 0.7 & 0.0 & 0.0 & 0.0 \\
\hline Geomyces sp. & 0.0 & 0.3 & 0.0 & 0.0 \\
\hline Gonatobotrys sp. & 8.5 & 9.0 & 1.8 & 2.0 \\
\hline Microsporum audouinii & 0.0 & 0.0 & 0.0 & 0.6 \\
\hline Microsporum nanum & 0.0 & 0.6 & 0.0 & 0.0 \\
\hline Mucor circinelloides & 0.0 & 0.6 & 0.0 & 0.0 \\
\hline Mucor racemosus & 4.6 & 1.9 & 3.2 & 2.2 \\
\hline Mycelia sterilia & 5.6 & 7.7 & 6.0 & 3.5 \\
\hline Oidiodendron griseum & 0.0 & 0.0 & 1.5 & 0.0 \\
\hline Paecilomyces sp. & 2.3 & 0.0 & 0.7 & 0.0 \\
\hline Paecilomyces variotii & 3.0 & 8.7 & 4.7 & 0.0 \\
\hline Penicillium brevissimum & 3.0 & 0.0 & 0.0 & 0.0 \\
\hline Penicillium chrysogenum & 1.6 & 0.0 & 1.1 & 0.0 \\
\hline Penicillium citreo-viride & 24.3 & 28.8 & 29.8 & 40.4 \\
\hline Penicillium citrinum & 0.0 & 0.0 & 0.7 & 0.0 \\
\hline Penicillium corylophilum & 1.0 & 0.0 & 0.0 & 0.6 \\
\hline Penicillium digitatum & 0.0 & 0.0 & 0.6 & 0.0 \\
\hline Penicillium expansum & 4.6 & 6.1 & 7.6 & 9.5 \\
\hline Penicillium funiculosum & 0.0 & 0.0 & 11.0 & 9.0 \\
\hline Penicillium glabrum & 9.8 & 13.5 & 11.4 & 0.0 \\
\hline Penicillium griseofulvum & 3.6 & 7.7 & 2.8 & 0.0 \\
\hline Penicillium lignorum & 0.7 & 0.0 & 0.0 & 0.0 \\
\hline Penicillium lilacinum & 12.5 & 2.2 & 2.8 & 14.8 \\
\hline Penicillium restrictum & 1.3 & 0.0 & 0.0 & 0.0 \\
\hline Penicillium sp. & 3.0 & 3.2 & 0.0 & 0.0 \\
\hline Penicillium tricolor & 1.3 & 3.2 & 0.0 & 0.0 \\
\hline Rhizopus sp. & 0.0 & 0.0 & 0.1 & 0.0 \\
\hline Rhizopus stolonifer & 1.6 & 1.9 & 0.0 & 0.0 \\
\hline Talaromyces macrosporus & 0.0 & 0.0 & 0.0 & 0.1 \\
\hline Trichoderma sp. & 1.6 & 0.0 & 1.4 & 0.0 \\
\hline Trichoderma viride & 0.0 & 0.0 & 0.4 & 0.0 \\
\hline Verticillium sp. & 1.0 & 0.0 & 3.1 & 1.0 \\
\hline Total & 100 & 100 & 100 & 100 \\
\hline
\end{tabular}


Table 4. Concentration of fungi in soil samples from organic and conventional rye crops

\begin{tabular}{ccccc}
\hline \multirow{2}{*}{ Sample no. } & \multicolumn{2}{c}{ Organic farming $\left[\times 10^{3} \mathrm{CFU} / \mathrm{g}\right]$} & \multicolumn{2}{c}{ Conventional farming $\left[\times 10^{3} \mathrm{CFU} / \mathrm{g}\right]$} \\
\cline { 2 - 5 } & PDA & MA & PDA & 82.5 \\
\hline 1 & 57 & 65 & 155 & 71.5 \\
\hline 2 & 56 & 84.5 & 115 & 66.5 \\
\hline 3 & 22.5 & 16.5 & 73.5 & 90.5 \\
\hline 4 & 51 & 44.5 & 87.5 & 129 \\
\hline 5 & 48 & 68.5 & 166 & 83.5 \\
\hline 6 & 43.5 & 74 & 88 & 152.5 \\
\hline 7 & 36 & 42.5 & 81 & 163.5 \\
\hline 8 & 66.5 & 63 & 87 & 151 \\
\hline 10 & 45 & 25 & 217 & 202.5 \\
\hline Mean & 60 & 32.5 & 176.5 & 119.3 \\
\hline
\end{tabular}

range from $24.5 \times 10^{3} \mathrm{CFU} / \mathrm{g}$ to $74.5 \times 10^{3} \mathrm{CFU} / \mathrm{g}$, and isolated on MA ranged from $0.5 \times 10^{3} \mathrm{CFU} / \mathrm{g}$ to $22 \times 10^{3}$ CFU/g. The concentration of fungi in samples of grain from conventional farms isolated on PDA was in the range from $7.5 \times 10^{3} \mathrm{CFU} / \mathrm{g}$ to $62 \times 10^{3} \mathrm{CFU} / \mathrm{g}$, and ranged from $9.5 \times 10^{3} \mathrm{CFU} / \mathrm{g}$ to $41.5 \times 10^{3} \mathrm{CFU} / \mathrm{g}$ on MA medium. In general, higher levels of fungi in grain samples from organic farms compared to conventional farms were isolated on PDA medium. However, on MA medium, the concentration of fungi is higher in samples from conventional farms (Table 2).

The following species of fungi had the largest share in samples of soil from organic farms: Penicillium citreo-viride (PDA - 24.3\%, MA - 28.8\%), Penicillium glabrum (PDA - 9.8\%, MA - 13.5\%), Penicillium lilacinum (PDA - 12.5\%, MA - 2.2\%), Gonatobotrys sp. (PDA - 8.5\%, MA - 9.0\%), and Paecilomyces variotii (PDA - 3.0\%, MA - 8.7\%). In the soil under rye crops from conventional farms the following fungi were dominant: Penicillium citreo-viride (PDA - 29.4\%, MA - 40.4\%), Penicillium lilacinum (PDA - 2.8\%, MA - 14.8\%), Penicillium glabrum (PDA - 11.4\%, MA - 0\%), Aspergillus versicolor (PDA - 3.2\%, MA - 9.8\%), Penicillium expansum (PDA - 7.6\%, MA - 9.5\%), Gonatobotrys sp. (PDA - 1.8\%, MA - 2.0\%), and Paecilomyces variotii (PDA - 4.7\%, MA - 0\%). The most diverse ones in species terms were soil isolates from both systems of rye crops isolated on PDA medium (Table 3).

The concentration of fungi in soil samples from organic rye crops isolated on PDA was in the range from $22.5 \times 10^{3} \mathrm{CFU} / \mathrm{g}$ to $66.5 \times 10^{3} \mathrm{CFU} / \mathrm{g}$, and isolated on MA ranged from $16.5 \times 10^{3} \mathrm{CFU} / g$ to $84.5 \times 10^{3} \mathrm{CFU} / \mathrm{g}$. The concentration of fungi in soil samples from conventional farms isolated on PDA was in the range from $73.5 \times 10^{3}$ $\mathrm{CFU} / \mathrm{g}$ to $217 \times 10^{3} \mathrm{CFU} / \mathrm{g}$, and on MA ranged from $66.5 \times$ $10^{3} \mathrm{CFU} / \mathrm{g}$ to $202.5 \times 10^{3} \mathrm{CFU} / \mathrm{g}$. In general, higher levels of fungi in soil samples from organic farms compared to conventional farms were found, isolated on both PDA and MA (Table 4).

The most frequently isolated fungi from organic rye grain, regardless of the media used, were species: Aureobasidium pullulans and Alternaria alternata. In conventional farms, most species isolated from rye grain were: Aureobasidium pullulans, Cladosporium oxysporum, Alternaria alternata and yeast-like fungi. Most often species isolated from the soil was Penicillium citreo-viride. According to Twarużek et al., dominant genera of fungi isolated from rye grain were Penicillium spp. and Aureobasidium spp., though Alternaria spp. also had a significant share [11].

\section{Classification of biosafety, BSL}

Isolated genera and species of fungi are ranked in terms of the existing danger to people doing different types of work in agriculture (Table 4). In 1996, the Working Group of the European Confederation of Medical Mycology established the classification of fungi in terms of biosafety [12]. The Classification of Biosafety Level (BSL) is the scale of potentially pathogenic fungi safety for humans and animals, and distinguishes three hazard classes represented by different species of fungi. Class BSL-1 includes saprophytes or plant pathogens causing superficial, non-invasive or mild threat. Class BSL-2 species are characterized by a relatively high ability to survive in the tissues of vertebrates, but in patients with severe immune disorders can cause deep and opportunistic infections. Pathogens of the class of BSL-3 are potentially capable of inducing severe deep fungal infections in apparently healthy individuals $[13,14]$ (Table 5).

Most frequently occurring fungi in grains of rye and soil sampled from the crop of rye mostly belong to class BSL-1. Among the isolated fungi, some of them have not been yet included in the classification of BSL, and some 
Table 5. Biosafety classification (BSL) of fungi potentially pathogenic to human, isolated from samples of rye grain and soil from the rye crops $[9,12,15,16]$

\begin{tabular}{|c|c|}
\hline Isolated fungi & Biosafety classification \\
\hline Acremonium sp. & 1 \\
\hline Acremonium strictum & I \\
\hline Alternaria alternata & 1 \\
\hline Alternaria chlamydospora & I \\
\hline Alternaria sp. & 1 \\
\hline Aspergillus candidus & 1 \\
\hline Aspergillus versicolor & I \\
\hline Aureobasidium pullulans & 1 \\
\hline Basipetospora rubra & ND \\
\hline Beauveria sp. & 1 \\
\hline Beltrania rhombica & ND \\
\hline Chaetomium atrobrunneum & 1 \\
\hline Chaetomium sp. & ND \\
\hline Cladosporium cladosporioides & $\mathrm{I}$ \\
\hline Cladosporium herbarum & 1 \\
\hline Cladosporium macrocarpum & ND \\
\hline Cladosporium oxysporum & 1 \\
\hline Cladosporium sphaerospermum & 1 \\
\hline Fusarium cerealis & ND \\
\hline Fusarium equiseti & ND \\
\hline Fusarium poae & ND \\
\hline Fusarium sp. & ND \\
\hline Fusarium tricinctum & ND \\
\hline Geomyces sp. & ND \\
\hline Gonatobotrys sp. & ND \\
\hline Microsporum audouinii & ND \\
\hline Microsporum nanum & ND \\
\hline Mucor circinelloides & II \\
\hline Mucor hiemalis & II \\
\hline Mucor plumbeus & 1 \\
\hline Mucor racemosus & $\mathrm{I}$ \\
\hline Mycelia sterilia & ND \\
\hline Nigrospora sp. & l \\
\hline Oidiodendron griseum & ND \\
\hline Paecilomyces sp. & ND \\
\hline Paecilomyces variotii & II \\
\hline Penicillium brevissimum & II \\
\hline Penicillium chrysogenum & ND \\
\hline Penicillium citreo-viride & I \\
\hline Penicillium citrinum & ND \\
\hline Penicillium corylophilum & $\mathrm{I}$ \\
\hline Penicillium crustosum & 1 \\
\hline Penicillium cyclopium & ND \\
\hline Penicillium digitatum & I \\
\hline Penicillium expansum & ND \\
\hline Penicillium funiculosum & 1 \\
\hline Penicillium glabrum & ND \\
\hline Penicillium griseofulvum & ND \\
\hline Penicillium lignorum & 1 \\
\hline Penicillium lilacinum & ND \\
\hline Penicillium nalgiovense & ND \\
\hline Penicillium restrictum & ND \\
\hline Penicillium rugulosum & ND \\
\hline Penicillium sp. & I \\
\hline Penicillium tricolor & 1 \\
\hline Penicillium verrucosum & ND \\
\hline Penicillium viridicatum & ND \\
\hline Rhizopus oryzae & ND \\
\hline Rhizopus sp. & 1 \\
\hline Rhizopus stolonifer & ND \\
\hline Talaromyces macrosporus & 1 \\
\hline Trichoderma sp. & ND \\
\hline Trichoderma viride & $\mathrm{I}$ \\
\hline Trichophyton sp. & 1 \\
\hline Ulocladium chartarum & II \\
\hline Verticillium sp. & 1 \\
\hline Yeast-like fungi & I \\
\hline
\end{tabular}

of them are in class BSL-II species that is particularly dangerous for people with immune deficiency.

\section{Discussion}

According to the research on health risks for farmers in conventional farms, which has been carried out for years at the Institute of Rural Health, fungi belonging to different genera and species, such as Penicillium spp., Mucor spp., Alternaria alternata, Cladosporium fulvum, Cladosporium herbarum, Aspergillus fumigatus, Aspergillus niger, Aspergillus candidus may be etiologic factors of allergic and immunotoxic diseases [17].

In this study most frequently isolated species was Aureobasidium pullulans, which may be found on the surface of plants. The infection with this species occurs mainly in the skin lesions, but the following were also noted corneal infections, pneumonia, generalized form in patients with severe immunodeficiency, superficial infection and peritoneal inflammation [9].

Numerous isolated fungi species present in the studied samples was Alternaria alternata species and genus Cladosporium spp. Seasonality of the occurrence of spores of $A$. alternata (high levels achieved in the summer) is due to the high availability of nutrients in the soil, a favorable temperature and humidity [18]. The spores of Alternaria spp. after entering the nose and the lungs may cause symptoms of hay fever or asthma. In the case of A. alternata and other fungi, primarily the spores cause allergy, while mycelium is less involved [19]. However, Alternaria alternata in comparison with Cladosporium herbarum, is characterized by a half lower content of spores in the air but it causes sensitization more often [20]. This is probably due to the fact that about $80 \%$ of $A$. alternata conidia present in the air are live cells, and Cladosporium herbarum cells are viable only in 20-30\% [21]. Another factor which differentiates the allergenicity of different species of fungi can be release of allergens after spore contact with the mucosal surface. It is believed that the $A$. alternata spore allergens are released with ease, while the release of allergens from spores of other species, such as Aspergillus fumigatus, requires the physical damage. Spore cell walls determine the availability of the allergen to the mucous membrane of the spore after getting into the airways [18]. Like other filamentous fungi A. alternata secrete also various secondary metabolites, including mycotoxins. Most mycotoxins are not sensitive to heat, and stable at the standard processes of preparing food and feed. They can be the cause of many animal diseases and health problems in humans after direct ingestion of moldy food [22].

Mold species of the genus Fusarium spp. were also quite often identified in rye and soil samples. These fungi are commonly found in soil as saprotrophs. They often develop on the remains of the plant and other organic substrates [23]. These fungi are dangerous to the health of humans and animals for the sake of mycotoxins having the toxic, carcinogenic, mutagenic properties [24]. 
In soil samples, fungi of the genus Penicillium are common. Penicillium spp. genus can cause infections, particularly in immunodeficient individuals. It is the etiologic agent of penicilliosis. This fungus also produces mycotoxins [9].

Organic dusts and especially harmful biological factors contained therein often lead to the formation of many respiratory diseases both immunotoxic (toxic syndrome caused by organic dust-ODTS, "sick house syndrome" - sick building syndrome) and allergic ones (extrinsic allergic alveolitis - EAA - alveolitis allergica, bronchial asthma, allergic rhinitis, allergic conjunctivitis, allergic dermatitis) [25-27].

Thermophilic actinomycetes (Thermoactinomyces vulgaris, T. viridis, T. sacchari, T. candidus, Saccharopolyspora rectivirgula $=$ Micropolyspora faeni $=$ Faenia rectivirgula), fungi spores (Alternaria spp., Aspergillus spp., Penicillium casei), protozoa, animal proteins, drugs, and some chemical compounds of low molecular weight play an important role in the development of EAA (farmer's lung disease) [28-30]. Initially, the disease is silent, leading to irreversible damage of the lung tissue. Patients complain of chronic cough and increasing shortness of breath. The disease may be acute or chronic, some also highlight the subacute form. Extrinsic allergic alveolitis is a disease of all age groups, also common in children and adolescents [25].

Upper respiratory tract allergies to common environmental allergens and occupational allergens of high and low molecular weight often precede the development of bronchial asthma. Atopic individuals often sensitize to occupational allergens of high molecular weight and their diseases are more severe [29, 31].

\section{Conclusions}

All the results of the research demonstrate the potential hazard to the health of people working in agriculture. Significant exposure of this professional group is associated with the presence of harmful biological agents present in the grain, and soil from its cultivation. The composition of these agents includes allergenic and toxinogenic molds.

Aspects of working in a non-agricultural sectors of the economy are understood much better, this is due to the fact that the same or similar activities are carried a greater group of people under the control of health and safety services and labor inspection and the employees benefit from an organized preventive health care provided by the occupational health service. Individual farmers are at a disadvantage, since there is no permanent monitoring system of the health (preventive examinations) of this professional group or monitoring of the health hazards in the work environment of a private farm in terms of quality and quantity. Other negative factors include: low health awareness among farmers and the level of knowledge of primary care physicians working in the country about the possible health risks encountered in agriculture. Knowing the advantages and disadvantages caused by molds for human health inspires to step up research aimed at improving the speed and efficiency of detection of respiratory diseases in farmers.

\section{Acknowledgments}

The study was funded by the National Science Centre on the basis of decision no. DEC-2011/01/B/NZ7/04300.

\section{References}

1. Socha K, Waszewska M. Organic producers in 2012 [Polish]. In: Knowledge and quality. Agricultural and Food Quality Inspection 2012; 3: 14-5.

2. Central Statistical Office. Statistical Yearbook of the Republic of Poland 2012, Warsaw.

3. Wittczak T. Allergic diseases and toxicological hazards in farmers' work environment [Polish]. Alergia 2012; 1: 12-4.

4. Kelishadi R, Poursafa P. Air pollution and non-respiratory health hazards for children. Arch Med Sci 2010; 6: 483-95.

5. Ramirez C. Manual and atlas of the Penicillia. Elsevier Biomedical Press, Amsterdam 1982.

6. Baran E. Outline of medical mycology [Polish]. Volumed, Wrocław 1998.

7. Larone DH. Medically important fungi. A guide to identification. ASM Press 2011.

8. Kwaśna H, Chełkowski J, Zajkowski P. Flora of Poland. Vol. XXII: Fungi [Polish]. W. Szafer Institute of Botany Polish Academy of Sciences, Cracow 1991.

9. Krzyściak P, Skóra M, Macura AB. Atlas of human pathogenic fungi [Polish]. MedPharm Poland 2011.

10. Samson RA, Hoekstra ES, Frisvad JC, Filtenborg O. Introduction to food- and airborne fungi. Centraalbureau voor Schimmelcultures. Utrecht, The Netherlands 2002.

11. Twarużek M, Grajewski J, Kwiatkowska J, et al. Mycological evaluation of cereals from organic and conventional systems of farming. Journal of Research and Applications in Agricultural Engineering 2012; 57: 159-63.

12. de Hoog GS. Risk assessment of fungi reported from humans and animals. Mycoses 1996; 39: 407-17.

13. Information of the Mycological Section Board of Polish Dermatological Society, Department of Dermatology and Venereology, Wroclaw Medical University [Polish]. Mikol Lek 1998, 5, Varia: 193-6.

14. Nowicki R, Korting HC. Differences in the hydrolitc activity of dermatophytes [Polish]. Mikol Lek 1995; 4: 209-13.

15. de Hoog GS, Zalar P, van den Ende BG, Gunde-Cimerman N. Relations of halotolerance to human-pathogenicity in the fungal tree of life: an overview of ecology and evolution under stress. In: Gunde-Cimerman N, Oren A, Plemenitaš A (eds.). Adaptation to life at high salt concentrations in Archaea, Bacteria, and Eukarya, Vol. 9. Springer, Dordrecht, 371-95.

16. Ziółkowska G, Tokarzewski S. Occurrence of moulds in reproductive goose flocks in southern-eastern Poland. Bull Vet Inst Pulawy 2007; 51: 553-61.

17. Żukiewicz-Sobczak W, Cholewa G, Krasowska E, et al. Pathogenic fungi in the work environment of organic and conventional farmers. Postep Derm Alergol 2012; 29: 256-62. 
18. Lipiec A. Fungi in the ethiology of allergic diseases [Polish]. Alergol Współcz 2002; 1: 10-4.

19. Nolard N. Mold allergy: 25 years of indoor and outdoor studies in Belgium. Allergy Immunol 2001; 33: 101-2.

20. Rapiejko P, Lipiec A, Modrzyński M. Treshold pollen concentration necessary to evoke allergic symptoms. Int Rev Allergol Clin Immunol 2004; 10: 91-4.

21. Govi V. Aerial diffusion of phytopathogenic fungi. Aerobiologia 1992; 8: 84-93.

22. Pokrzywa P, Cieślik E, Topolska K. The evaluation of mycotoxins content in selected food product [Polish]. Żywność Nauka Technologia Jakość 2007; 3: 139-46.

23. Nelson PE. Fusarium. APS Press, St. Paul, Minnesota 2002; 1-392.

24. Gang G, Miedaner U, Schuhmacher U, et al. Deoxynivalenol and nivalenol production by Fusarium culmorum isolates differing in aggressiveness towards winter rye. Phytopathology 1998; 88: 879-84.

25. Dutkiewicz J, Skórska C, Mackiewicz B, Cholewa G. Prevention of diseases due to organic dust in agriculture and food industry [Polish]. Institute of Rural Health, Lublin 2000; 24-7.

26. Głowacka A, Przychodzień A, Szwedek A. Potentially human and animal-pathogenic fungi from forest recreational grounds of tódź precinct [Polish]. Mikol Lek 2007; 14: 89-94.

27. Cudowska B, Marcinkiewicz S, Kaczmarski M. Sensitization to cereal allergens in children with atopic dermatitis. Postep Derm Alergol 2011; 28: 181-6.

28. Żukiewicz-Sobczak W. The role of fungi in allergic diseases. Postep Derm Alergol 2013; 30: 42-5.

29. Pałczyński C, Kieć-Świerczyńska M. Allergology and clinical toxicology. Clinical Occupational Medicine. J. Nofer Institute of Occupational Medicine, Łódź 2000; 47, 73-74.

30. Żukiewicz-Sobczak W, Sobczak P, Krasowska E, et al. Allergenic potential of moulds isolated from buildings Ann Agric Environ Med 2013; 20: 500-3.

31. Jenerowicz D, Silny W, Dańczak-Pazdrowska A, et al. Environmental factors and allergic diseases. Ann Agric Environ Med 2012; 19: 475-81. 